\title{
Implementasi K-Nearest Neighbor Dalam Prediksi Mahasiswa Berhenti Kuliah
}

\author{
Yunita* \\ STMIK Widya Cipta Dharma, Samarinda, Indonesia \\ Email: *yunita@wicida.ac.id \\ Email Penulis Korespondensi: yunita@wicida.ac.id
}

\begin{abstract}
Abstrak-Mahasiswa merupakan seorang pelajar yang duduk dan terdaftar pada salah satu perguruan tinggi baik negeri maupun swasta, menjadi seorang mahasiswa merupakan impian banyak pelajar diseluruh dunia dan menjadi mahasiswa merupakan gerbang awal untuk menentukan seseorang akan menggeluti dunia keilmuan dalam bidang apa, baik ilmu komputer, kedokteran, dunia pendidikan dan lain-lainnya. Namun sangat banyak penyebab mahasiswa memutuskan untuk berhenti mengikuti perkuliahan secara tiba-tiba yang diakibatkan leh beberapa faktor, baik faktor external maupun faktor internal. Hal tersebut menyebabkan kerugian tersendiri yang akan dihadapi oleh kampus salah satunya berkurangnya kuantitas data mahasiswa dan mengakibatkan penumpukan data, diperlukan prediksi mahasiswa yang berpotensi berhenti kuliah secara sepihak dengan melihat beberapa kriteria dan menggali informasi terhadap data mahasiswa yang berpotensi untuk berhenti kuliah dengan menerapkan algoritma K-NN. Pada penelitian ini algoritma K-NN merekam data lama dan melihat kemiripan terhadap data baru dalam upaya pengenalan pola mahasiswa berhenti kuliah, hasil yang didapatkan dari data kuliah baru menunjukan kemiripan data dengan data lama mahasiswa yang berhenti kuliah dengan kemiripan nilai terdekat dari kasus lainnya yaitu 17,3815 dengan 19,98875 sehingga hasil yang didapatkan keputusan mahasiswa data baru tersebut memutuskan kemungkinan berhenti kuliah.
\end{abstract}

Kata Kunci: Data Mining; K-NN; Mahasiswa Berhenti Kuliah

\begin{abstract}
A student is a student who sits and is registered in one of the universities, both public and private, being a student is the dream of many students around the world and being a student is the starting gate to determine someone will be in the world of science in what field, be it computer science, medicine, world of education and others. However, there are many reasons why students decide to stop attending lectures suddenly due to several factors, both external and internal factors. This causes its own losses that will be faced by the campus, one of which is the reduction in the quantity of student data and resulting in data accumulation, it is necessary to predict students who have the potential to stop studying unilaterally by looking at several criteria and digging up information on the data of students who have the potential to quit college by applying the K-algorithm. NN. In this study, the K-NN algorithm records old data and sees similarities to new data in an effort to recognize patterns of students dropping out of college, the results obtained from new lecture data show that the data is similar to the old data of students who dropped out of college with the closest similarity of values from other cases, namely 17.3815 with 19.98875 so that the results obtained by the new data student decision decided the possibility of dropping out of college.
\end{abstract}

Keywords: Data Mining; K-NN; Students Quit College

\section{PENDAHULUAN}

Pendidikan merupakan suatu proses yang membantu manusia untuk memperoleh pengetahuan, pengalaman, didikan etika, kehidupan dan masa depan, pendidikan merupakan jenjang dan tahapan yang banyak diterima oleh masyarakat luar dan pendidikan menjadi identitas diri manusia itu sendiri, dengan adanya pendidikan yang sudah diakui oleh bayak pihak maka pendidikan pada akhirnya menjadi patokan terhadap pengetahuan dan jabatan seseorang dikalangan masyarakat luas sehingga banyak masyarakat yang berlomba-lomba ingin memperoleh pendidikan sampai pendidikan tingkat tinggi. Banyak masyarakat yang mempersiapkan keuangan demi mendapatkan anaknya atau diri sendiri untuk memperoleh pendidikan tinggi, banyak rintangan ketika seseorang menduduki pendidikan khususnya pendidikan tinggi membuat peserta didik banyak yang disebut dengan mahasiswa memilih untuk berhenti melanjutkan pendidikannya[1].

Kasus mahasiswa berhenti kuliah merupakan kasus yang tidak asing lagi dan sering terjadi dalam perkuliahan. Berhentinya mahasiswa juga disebabkan banyak factor, baik faktor akademik, non akademik ataupun dari personalnya yang menyebabkan serta mempengaruhi mahasiswa tersebut untuk berhenti kuliah, jenis berhenti kuliah ada beberapa tahapan seperti. Berhentinya mahasiswa dari perkuliahan tidak hanya merugikan diri mahasiswa itu secara personal saja, tetapi berdampak juga akepada perguruan tinggi seperti bertambahnya pengurangan mahasiswa, tidak diketahuinya mahasiswa yang memilih berhenti kuliah sehingga terjadinya penumpukan data hal tersebut juga akan mempersulit dosen dalam mengetahui mahasiswa kelas mana yang harus dibuang[2][3].

Perlu melakukan sebuah prediksi tentang faktor-faktor yang mempengaruhi berhentinya mahasiswa dari perkuliahan. Agar dapat mengurangi permasalahan tersebut dan juga dapat melakukan tindak lanjut terhadap mahasiswa yang memilih berhenti memutuskan perkuliahan salah satunya dengan menggunakan teknik prediksi dalam Algoritma K-NN, dimana Algoritma KNN merupakan sebuah proses untuk menemukan pengetahuan yang menarik dari data berhentinya mahasiswa[4][5]. 
Penelitian terdahulu memerlihatkan algoritma KNN sangat membantu dalam banyak permasalahan seperti memperlihatkan klasifikasi tingkat stres seseorang melalui tweet yang ada pada akun twitter, pada tahapan ini data dilakukan seleksi fitur terlebih dahulu terhadap data status yang ada pada twitter dan dilakukan klasifikasi terhadap tingkat stress pemilik akun dengan metode $\mathrm{KNN}$, terhlihat metode $\mathrm{KNN}$ mampu menyelesaikn permasalahan klasifikasi dengan baik[6].

Penelitian terdahulu memperlihatkan algortima KNN dalam menentukan pemberian pinjaman kredit pensiunan yang memberikan hasil terbaik dari setiap keputusan dan mampu megklasifikasikan data berdasarkan kriteria yang sudah ditentukan[7]. Penelitian lainnya metode ini juga digunakan dalam memprediksi cuaca di kota Palembang dimana jejak data rekaman cuaca yang ada dikota Palembang dilakukan klasifikasi menggunakan algoritma KNN untuk mempermudah memprediksi kejadian terhadap cuaca dimasa yang akan mendatang[8].

Pada penelitian ini metode K-NN digunakan sebagai tahapan klasfikasi dalam menentukan mahasiswa yang akan berhenti kuliah secara sepihak untuk membantu perguruan tinggi dalam menghindari permasalahan yang telah disebutkan sebelumnya, menggunakan metode KNN dikarenakan banyak penelitian yang lainnya menyatakan tingkat akurasi dan pengenalan pola yang baik terhadap kasus yang lama dalam menyelesaikan permasalahan baru.

\section{METODOLOGI PENELITIAN}

Metodologi pada penelitian ini merupakan tahapan yang menunjukan penelitian terhadap hal yang akan dicapai dan tahapan apa yang termasuk dalam proses penelitian, penelitian ini melakukan pengumpulan data mulai dari tahapan pengambilan data dan tapan penjelasan berupa teoristis yang terkait dengan penelitian, penelitian ini mengunakan metode kuantitatif [9][10].

\subsection{Pengumpulan dan Pengolahan Data}

Tahapan penelitian ini melakukan pengumpulan dan data dengan cara sebagai berikut ini[11][12]:

1. Observasi

Observasi merupakan tahapan penelitian dalam pengumpulan data secara langsung, mengamati langsung untuk mendapatkan hasil yang terpercaya.

2. Dokumentasi

Hal ini perlu dilakukan untuk mendapatkan data yang direkam di dalam sebuah data file, record dan lain-lain, fungsi dari data ini merupakan bukti dari adanya hal yang menjadi landasan dari penelitian ini.

3. Studi Pustaka

Studi pustaka untuk melengkapi data teoristis dan data yang memperlihatkan penelitian terdahulu sebagai arahan kemana penelitian ini akan dilakukann.

4. Analisa

Analisa pada penelitian ini melihat kepada permasalahaan yang menjadi topik utama untuk diketahui tahapan apa yang selanjutnya akan dilakukan, sebagai bentuk penyelesaian permasalahan dengan memanfaatkan ilmu komputer dan memilih tahapan dan metode yang akan dilakukan pada proses penyelesaian permasalahan[13].

5. Tahapan pengujian

Tahapan pegujian digunakan metodologi kuantitatif dimana metode ini menampilkan hasil matematik. Hasil yang didapatkan merupakan hasil dari penggunaan metode K-Nearest Neighbor, hasil sebagai keputusan pada penelitian ini.

6. Kesimpulan

Kesimpulan dilakukan dengan memberitahu hasil dan poin-poin penting dalam penelitian secara terperinci, tepat, singkat dan padat

\subsection{K-Nearest Neighbor $(\mathrm{KNN})$}

Adapun tahapan dalam penyelesaian permasalahan menggunakan metode K-nearest Neighbor, sebagai berikut ini[14]-[17]

1. Menentukan parameter $\mathrm{K}$, parameter ini nantinya akan menadi bahan utama dalam batasan yang akan dilakukan pencarian dengan menggunakan metode ini, agar penelitian dan penelitian ini memiliki pondasi awal dari gambaran hal yang ingin ditemukan.

2. Menghitung kuadrat jarak euclidian masing-masing obyek terhadap data sampel yang diberikan

3. Mengurutkan objek-objek tersebut ke dalam kelompok yang mempunyai jarak euclid terkecil

4. Mengumpulkan kategori $Y$

5. Dengan menggunakan kategori mayoritas,maka dapat diprediksikan nilai query instance yang telah dihitung

$\mathrm{Dij}=\sqrt{x i i-x i i)+x 2 i-x 2 i+\cdots(x i i-x 2 i)}$ 
JURNAL MEDIA INFORMATIKA BUDIDARMA

Volume 5, Nomor 3, Juli 2021, Page 866-869

ISSN 2614-5278 (media cetak), ISSN 2548-8368 (media online)

Available Online at https://ejurnal.stmik-budidarma.ac.id/index.php/mib

DOI 10.30865/mib.v5i3.3049

Keterangan :

Dij=Jarak dari data ke i ke pusat cluster i

$\mathrm{Xxi}=$ Data dari data ke- $\mathrm{i}$ keattribute data data $\mathrm{ke}-\mathrm{K}$

$\mathrm{Xkj}=$ Data dari data ke- $\mathrm{j}$ keattribute data data $\mathrm{ke}-\mathrm{K}$

\section{HASIL DAN PEMBAHASAN}

Salah satu program pemerintah untuk membantu masyarakat yang belum mempunyai rumah adalah dengan meluncur program perumahan bersubsidi dengan bunga cicilan hanya sekitar 5\% program tersebut disalurkan melalui bank yang bekerja sama dengn pemerintah data

\subsection{Studi Kasus dan Penyelesaian}

Pertama: tentukan terlebih dahulu jumlah jarak yang akan menjadi parameter, pada peneitian ini menjadi 3 (Tiga) Jumlah tetangga terdekat $(\mathrm{K}=3)$

Tabel berikut merupakan data mahasiswa yang berhenti kuliah

Tabel 1. Data Mahasiswa Yg Berhenti Kuliah

\begin{tabular}{cccccc}
\hline No & Nama & Semester & Penghasilan/Jam & IPK & Keterangan \\
\hline 1 & Lilis & 2 & Rp.2500 & 3.55 & Lanjut \\
2 & Yeni & 4 & Rp.2600 & 2.92 & Berhenti \\
3 & Putri & 4 & Rp.2700 & 3.40 & Berhenti \\
4 & Putra & 2 & Rp.2800 & 2.95 & Berhenti \\
5 & Roni & 4 & Rp.2900 & 3.20 & Lanjut \\
\hline
\end{tabular}

Pertanyaan seorang calon mahasiswa baru dengan data sebagai berikut:

Tabel 2. calon mahasiswa baru

\begin{tabular}{cccccc}
\hline No & Nama & Jurusan & Penghasilan & IPK & Keterangan \\
\hline 1 & Santi & T.Informatika & Rp.2400 & 3.4 & $? ?$ \\
\hline
\end{tabular}

Berdasarkan data sebelumnya apkah mahasiswa baru diatas lanjut atau berhenti kuliah.

Kedua : Proses perhitungan jarak menggunakan persamaaan euclidean Distance

$$
\begin{aligned}
\mathrm{d}\left(\mathrm{x}_{3}, \mathrm{C}\right)= & \sqrt{(a-c a)+(b-c b)+(c 1-c 2)+(d 2-c d)} \\
& =\sqrt{(2500-2400)+(1-1)+(3-3)+(2-4)}=10,00075 \\
\mathrm{~d}\left(\mathrm{x}_{2}, \mathrm{C}\right)= & \sqrt{(a-c a)+(b-c b)+(c 1-c 2)+(d 2-c d)} \\
& =\sqrt{(2600-2400)+(2-1)+(2-3)+(2-4)}=14,19577 \\
\mathrm{~d}\left(\mathrm{x}_{4}, \mathrm{C}\right)= & \sqrt{(a-c a)+(b-c b)+(c 1-c 2)+(d 2-c d)} \\
& =\sqrt{(2700-2400)+(1-1)+(3-3)+(2-4)}=17,37185 \\
\mathrm{~d}\left(\mathrm{x}_{5}, \mathrm{C}\right)= & \sqrt{(a-c a)+(b-c b)+(c 1-c 2)+(d 2-c d)} \\
& =\sqrt{(2800-2400)+(1-1)+(3-3)+(2-4)}=19,98875 \\
\mathrm{~d}\left(\mathrm{x}_{6}, \mathrm{C}\right)= & \sqrt{(a-c a)+(b-c b)+(c 1-c 2)+(d 2-c d)} \\
& =\sqrt{(2900-2400)+(1-1)+(3-3)+(2-4)}=22,40089
\end{aligned}
$$

Setelah dihitung jaraknya,selanjutnya urutkan nilai dari terkecil ke nilai yang terbesar seperti berikut:

Penyelesaian:

Algoritma K-NN tidak dapat memproses nilai atributkriteria dalam bentuk huruf oleh karna itu nilai atribut dirubah dalam bentuk variabel angkat seperti berikut:

atribut jurusan

Tabel 4. calon mahasiswa setelah diubah kedalam angka

\begin{tabular}{ccclcc}
\hline No & Nama & Semester & Penghasilan & IPK & Keterangan \\
\hline 1 & Lilis & 2 & Rp. 2500 & 3.55 & Lanjut \\
2 & Yeni & 4 & Rp. 2600 & 2.92 & Berhenti \\
3 & Putri & 4 & Rp.2700 & 3.40 & Berhenti \\
\hline
\end{tabular}


JURNAL MEDIA INFORMATIKA BUDIDARMA

Volume 5, Nomor 3, Juli 2021, Page 866-869

ISSN 2614-5278 (media cetak), ISSN 2548-8368 (media online)

Available Online at https://ejurnal.stmik-budidarma.ac.id/index.php/mib

DOI 10.30865/mib.v5i3.3049

\begin{tabular}{ccclcc}
\hline No & Nama & Semester & Penghasilan & IPK & Keterangan \\
\hline 4 & Putra & 2 & Rp.2800 & 2.95 & Berhenti \\
5 & Roni & 4 & Rp.2900 & 3.20 & Lanjut \\
\hline
\end{tabular}

Berikut adalah data calon mahasiswa baru setelah berubah dalam bentuk variabel seperti berikut:

Tabel 5. Hasil

\begin{tabular}{llllll}
\hline No & Nama & Semester & Penghasilan & Ipk & Keterangan \\
\hline 1 & Santi & 2 & Rp.2400 & 3.4 & Berhenti \\
\hline
\end{tabular}

pada hasil tabel diatas tampak hasil menunjukan kecenderungan dari nilai terdekat denga nilai lainnya berakhir kepada hasil mahasiswa tersebut bernama santi melanjutkan perkuliahanya.

\section{KESIMPULAN}

Dengan dibuatnya penelitian ini, kita dapat mengetahui tingkat prediksi mahasiswa berhenti kuliah, yang cukup sering terjadi pada lingkungan masyarakat, baik itu dari segi pendapatan dan pembiyaan hidup serta kebutuhan lain yang meningkatkan faktor mahasiswa memutuskan untuk berhenti kuliah. Dengan digunakannya metode ini, prediksi mahasiswa berhenti kuliah yang tentunya dapat mempermudah banyak kalangan untuk lebih mengetahui penyebab mahasiswa yang berhenti kuliah secara sepihak dan sering kali membuat pihak kampus mengalami kerugian bahkan keterlambatan dalam pelaporan data mahasiswa. Pada hasil data diatas memerlihatka perkiraan mahasiswa akan berhenti kuliah, ternyata lebih cederung kepada tetap lanjut perkuliahan.

\section{REFERENCES}

[1] K. Arizona, Z. Abidin, and R. Rumansyah, "Pembelajaran Online Berbasis Proyek Salah Satu Solusi Kegiatan Belajar Mengajar Di Tengah Pandemi Covid-19," J. Ilm. Profesi Pendidik., vol. 5, no. 1, pp. 64-70, 2020.

[2] M. A. Firmansyah, "Analisis Hambatan Belajar Mahasiswa Pada Mata Kuliah Statistika," J. Penelit. dan Pembelajaran Mat., vol. 10, no. 2, 2017.

[3] M. Muhamad, A. P. Windarto, and S. Suhada, "Penerapan Algoritma C4.5 Pada Klasifikasi Potensi Siswa Drop Out," KOMIK (Konferensi Nas. Teknol. Inf. dan Komputer), vol. 3, no. 1, pp. 1-8, 2019.

[4] D. A. Anggoro and N. D. Kurnia, "Comparison of accuracy level of support vector machine (SVM) and K-nearest neighbors (KNN) algorithms in predicting heart disease," Int. J. Emerg. Trends Eng. Res., vol. 8, no. 5, pp. 1689-1694, 2020 .

[5] E. P. W. Mandala, "Data Mining Algoritma Nearest Neighbor Untuk Memprediksi Tingkat Resiko Pinjaman Dana Di Bank Perkreditan Rakyat," JIK J. Ilmu Komput., vol. 1, no. 2, pp. 91-103, 2016.

[6] M. I. Maulana and A. A. Soebroto, "Klasifikasi Tingkat Stres Berdasarkan Tweet pada Akun Twitter menggunakan Metode Improved k-Nearest Neighbor dan Seleksi Fitur Chi- square,” vol. 3, no. 7, pp. 6662-6669, 2019.

[7] V. Alfani, "Data Mining Untuk Klasifikasi Pinjaman Kredit Pensiunan Menggunakan Algoritma K-Nearest Neighbor," J. Pelita Inform., vol. 18, no. April, pp. 281-286, 2019.

[8] J. T. Informatika and U. Sriwijaya, "Prediksi Cuaca di Kota Palembang Berbasis," pp. 9-18.

[9] Albi Anggito and Johan Setiawan, Metodologi Penelitian Kuantitatif. Jawa Barat: CV Jejak, 2018.

[10] G. Hendro, T. B. Adji, and N. A. Setiawan, "Penggunaan Metodologi Analisa Komponen Utama ( PCA ) untuk Mereduksi Faktor-Faktor yang Mempengaruhi Penyakit Jantung Koroner,”Semin. Nas. ScrETec, pp. 1-5, 2012.

[11] E. W. Winarni, Teori dan Praktik Penelitian Kualitatif dan Kuantitatif PTK dan R\&D. Jakarta: Bumi Aksara, 2018.

[12] E. Buulolo, Data Mining Untuk Perguruan Tinggi. Deepublish, 2020.

[13] M. P. Simatupang and D. P. Utomo, "Analisa Testimonial Dengan Menggunakan Algoritma Text Mining Dan Term Frequency- Inverse Document Frequence (Tf-Idf) Pada Toko Allmeeart," KOMIK (Konferensi Nas. Teknol. Inf. dan Komputer), vol. 3, no. 1, pp. 808-814, 2019.

[14] Y. Zhang, G. Cao, B. Wang, and X. Li, “A novel ensemble method for k-nearest neighbor,” Pattern Recognit., vol. 85, pp. 13-25, 2019.

[15] M. R. Islam, A. R. M. Kamal, N. Sultana, R. Islam, M. A. Moni, and A. Ulhaq, "Detecting Depression Using K-Nearest Neighbors (KNN) Classification Technique," Int. Conf. Comput. Commun. Chem. Mater. Electron. Eng. IC4ME2 2018 , no. February, pp. 1-4, 2018.

[16] M. T. Masud, M. A. Mamun, K. Thapa, D. H. Lee, M. D. Griffiths, and S. H. Yang, "Unobtrusive monitoring of behavior and movement patterns to detect clinical depression severity level via smartphone," J. Biomed. Inform., vol. 103, 2020.

[17] A. Adiwijaya, M. N. Aulia, M. S. Mubarok, U. N. W, and F. Nhita, "A Comparative Study of MFCC-KNN and LPC-KNN for Hijaiyyah Letters Pronounciation Classification System," in International Conference on Information and Communication Technology (ICoICT), 2017. 